\title{
Educators' perceptions, attitudes and practices: blended learning in business and management education
}

\author{
Vladlena Benson $^{\mathrm{a}}$, Deborah Anderson ${ }^{\mathrm{a}}$ and Ann Ooms ${ }^{\mathrm{b} *}$ \\ ${ }^{a}$ Kingston Business School, Kingston University, Kingston upon Thames, UK; ${ }^{b}$ Faculty of \\ Health and Social Care Sciences, Kingston University and St George's, University of \\ London, London, UK
}

(Received 7 October 2010; final version received 28 April 2011)

\begin{abstract}
Adoption of blended learning is a complex process for higher education institutions and academic staff. Although the move towards blended learning is generally instigated at institutional level, factors determining its success and minimising resistance of faculty often emerge at delivery level. This paper explores adoption of blended learning practices in a Business School at a university in the United Kingdom. Based on the interviews with a purposive sample of 16 academic staff members delivering 36 business modules, this case study explores the concept of blended learning from the academic staff's perspective. A typology of three distinct approaches to blended learning - 'Technology is all', 'Bolt-ons' and 'Purely pedagogic' - emerged from the data extending understanding of blended learning practices. A team of three researchers conducted the study. Two of the researchers were academic staff members from the Business School and one researcher was an academic staff member from another faculty within the same university.
\end{abstract}

Keywords: blended learning; business education; higher education; educational technology

\section{Introduction}

The notion of blending various teaching methods to achieve an effective learning experience has been a subject of past and present exploration by academics. Adding creative and innovative uses of technology to improve teaching practices have generated new opportunities for learning (for example, Clark 2003). Blended learning is envisaged to maximise the benefits of traditional teaching methods and online delivery. Vaughan (2007) contests this assumption and stresses significant difficulties and risks associated with technology uses in learning and teaching. The problems that arise in developing blended learning modules include insufficient support, lack of time and resources for course development, risks associated with availability of technology and the necessity of acquiring new teaching and technology skills. Evidence of challenges impeding the adoption of technology by instructors (Derntl and Motschnig-Pitrik 2005) motivated the researchers to investigate approaches of blended learning at the module level (one module is equivalent to 15 or 30 credits) and explore the concept of blended learning from the perspective of academic staff at the Business School at one post-1992 university in the United Kingdom.

*Corresponding author. Email: a.ooms@sgul.kingston.ac.uk 
The definition of blended learning provided by Williams (2002) as the combination of face-to-face and online learning has been contested by some researchers as insufficient because it involves 'bolting on' technology into traditional course as an add-on or extra content and ignores the need of rethinking the course design or pedagogy (Bleed 2001; Vaughan 2007). Delivery of blended learning courses involves a move of a significant portion of the learning activities online. A blend of traditional methods (i.e. face-to-face classroom teaching), with technology-based instruction, including online communication, activities and delivery, entails significant changes to the course delivery; for example, leading to shorter 'seat-time' (Garrison, Kanuka, and Howes 2002). These courses are distinct from 'distance learning' courses offered online or at a distance, as emphasised by Dziuban, Hartman, and Moskal (2004). Blended learning is significantly different to courses delivered in a traditional face-to-face classroom with a supplemental website. It is not implemented by a simple transfer of teaching materials online, but rather involves redesign of delivery and pedagogy (Vaughan 2007).

Taking into consideration the arguments above, the definition of blended learning as a significant "integration of online and traditional face-to-face class activities" (Alebaikan and Troudi 2010, 50) is sufficient for the scope of this paper. This study aims to investigate perceptions, attitudes and practices related to blended learning in higher education and to identify factors that facilitate or impede adoption and implementation of blended learning at the delivery level at the Business School at one university based in London, UK.

The following research questions are addressed:

(a) What are academic staff perceptions of blended learning?

(b) What are academic staff attitudes towards blended learning?

(c) What are academic staff current practices of blended learning?

By exploring the staff perspective on blended learning, this case study can inform those managing, planning and taking initiatives in professional development that includes blended delivery.

\section{Blended learning: benefits and risks}

Persistent attention from researchers to blending technology with traditional delivery is related to practitioner beliefs that technology brings a greater level of effectiveness into learning and teaching. Technology has had a significant influence on the ways students interact with their peers, faculty and transformed learning and teaching inside and outside of the traditional classroom. Research suggests that information and communication technology can help remove geographical and situational learning barriers, offer better opportunities for learner and instructor interaction and lead to raising the quality of learning experiences (Bates 2000; Garrison and Anderson 2003).

A mix of different pedagogies and teaching strategies has been regarded as good practice for many years. Lectures are no longer the standard, and teaching involves more classroom interaction, case studies, student group work and presentation, simulations and other types of learning activities (Williams 2002). Blended learning offers an effective platform for employing different pedagogical strategies and has 
the potential to maximise the advantages of both face-to-face and online learning (Wu, Tennyson, and Hsia 2010). The studies conducted at the University of Tennessee and Stanford University show that blended learning can improve learning outcomes. These findings were confirmed by a study undertaken at two higher education institutions in the United Kingdom (Boyle et al. 2003). Also in the United Kingdom, a review of UK literature and practice commissioned by the Higher Education Academy concluded that overall students are very positive about blended learning (Sharpe et al. 2006). In addition, blended learning produced a stronger sense of community among students than traditional face-to-face or online learning (Rovai and Jordan 2004). Students' interaction and overall satisfaction have been shown to improve through blended learning (DeLacey and Leonard 2002). Research conducted by Garrison and Kanuka concludes that "blended learning is consistent with the values of traditional higher education institutions and has the proven potential to enhance both the effectiveness and efficiency of meaningful learning experiences" (2004, 5). Finally, the role of instructor transforms from teacher to facilitator, as they take charge of learning the new technology, adapting the technology to pedagogy or even forging new pedagogical principles based on innovations in technology, as discussed in Charles and Anthony (2007). On the other hand, there is evidence of staff reluctance in adopting technology to support/replace faceto-face teaching (Ooms et al. 2008). Whether this reluctance is a result of disbelief in technology, lack of supporting resources or perception of lower quality, it can certainly influence the implementation of a blended learning strategy. Academic staff encounter the challenge of how to effectively integrate technology in their teaching practices (Arbaugh 2008). Faced with a range of diverse tools including multimedia, mobile technologies, Web 2.0 resources and services, and social networks, academic staff need to make informed decisions on how to use these technologies in their teaching.

A willingness to accept new technologies could significantly affect the success of blended learning development. Charles and Anthony (2007) report that core faculty perceive the development of online-based activities as time-consuming and are more likely to shy away from technology-facilitated interactions. A preparation time of at least six months is suggested for blended learning integration with a great impetus on encouraging academics to apply blended learning pedagogy and exchange good practices from those experienced in the effective use of blended learning (Charles and Anthony 2007). As a result, institutions need to identify 'early adopters' and 'laggards' in the innovation process (Rogers 1995) and develop strategies as to how blended learning may address their requirements in the changing educational landscape. Blended learning developments take time, and the amount of work involved, even when given support by e-developers, can be underestimated by those staff who are new to blended learning (Ooms et al. 2008). Research indicates that the insufficient time due to contextual factors such as the structure of timetables and workload, and a lack of proper training can cause delays and ineffective use of technology in education (Cuban, Kirkpatrick, and Peck 2001; Pajo 2001). A combination of technological and pedagogic training is desirable (Hannon 2008; Oliver et al. 2004; Higher Education Funding Council for England. 2005), and academic staff development becomes most successful when supported by a range of strategies (Bates 2000).

Lacking in the current literature are studies about educators' perceptions of blended learning, their attitudes towards blended learning and their current blended 
learning practices. Faculty scepticism and misunderstandings about what blended learning includes are not uncommon and are factors that could hinder blended learning developments (Ooms et al. 2008). This study aims to fill this gap in the literature by investigating perceptions, attitudes and practices of blended learning of academic staff in business higher education.

\section{Research method}

A case-study methodology was used to investigate academic staff perceptions and attitudes towards blended learning and current blended learning practices. Data were collected through semi-structured interviews with 16 academic staff. The focus of the qualitative interviews was to explore the practices of blended learning implementation at a business school in a UK university by unfolding the meaning of blended learning experiences from the staff perspective. In addition, secondary data, such as the faculty and university strategies on quality enhancement and blended learning were analysed, providing insight into the institutional context.

The interviewing investigation comprised seven stages: thematising, designing, interviewing, transcribing, analysing, verifying, and reporting (Kvale 1996). The first two stages were informed by the theoretical framework and secondary data providing an insight into the institutional context. Three pilot interviews were conducted initially and were followed by some adjustments to the interview schedule. The interviewing method stage involved semi-structured interviews with academic staff from schools of Business and Law from a wide range of departments and subject areas.

Purposive sampling was used to sample 16 academic staff members from postgraduate and undergraduate programmes, in order to obtain a representative sample of class sizes; that is, from small (25 students and under) to large (100 students and over). A subset of 16 interviews of those academic staff engaged in undergraduate programmes and modules offered on the MBA, where blended learning strategy was in the first year of its implementation, were selected. This subset of interviewed academic staff covered 36 modules. Interviews were conducted at the university. The interviews were digitally recorded, transcribed, and then checked with interviewees for accuracy.

Primary analysis was conducted by focusing on specific questions relating to innovation, perceptions of blended learning and attitudes to technology. Findings are reported by drawing upon (anonymised) quotations. The next stage of analysis developed a categorisation of the different perceptions leading to a range of approaches to blended learning, and involved identifying similarities and differences amongst participants. Whilst this approach does not enable the research to make any claims about objectivity and generalisability, it does allow a detailed, in-depth understanding of the current perceptions, attitudes and practice relating to blended learning at this institution.

\section{Findings}

What are academic staff perceptions of blended learning?

Analysis of the interview transcripts suggested that there is almost universal support for offering a range of learning resources to students. A perception that young 
people (students) like "to break things up" (Participant 2) appears to have led to academic staff considering a variety of tools and techniques in the delivery of their modules. Some participants saw this as "blended learning" that may or may not be information and communications technologies (ICT) based:

Yes, I mean my blended learning does not necessarily have to do with ICT, but I do use a variety of techniques in a sense; it's partly group discussion, partly it's lecture, partly it's individual work, so it is blended although the blended is not mainly based [...] on ICT. (Participant 15)

This perception of blended learning as more than just technology was a common feature of several interviews; upon answering a question on their understanding of blended learning:

That blended learning is everything thrown in, not just information technology but it's individual work, it's group work, it's quizzes, it's questionnaires, it's reading, it's case studies, it's role play ... independent learning, you know, all of it. (Participant 16)

Whilst most academic staff interviewed understood the inclusion of some technology implied in definitions of blended learning, for many of them blended learning was much wider than simply amalgamating a number of electronic and web-based tools. A number commented on the fact that they had always approached their teaching by considering variety in delivery. Conclusions of the study confirm earlier findings (Oliver and Trigwell 2005) that blended learning is not understood uniformly by academic staff, and a mixture of its definitions exist in this case study.

\section{What are academic staff attitudes towards blended learning?}

Despite concerns, participants demonstrated an appreciation of many benefits of an ICT-based blended learning approach. For Participant 16, blended learning:

makes it more interesting. For the students [...] it also covers all learning styles because we don't all learn in one particular way ... and it gives different angles to things as well, it helps you see it from the other side.

Similarly, Participant 14 commented:

[...] I think one of the clear benefits of thinking of other ways of making the module more relevant, [is] more engaging, more motivating for the students.

One theme that did emerge from a number of interviews was the idea that sophisticated technology could not be a substitute for poor teaching. The importance of execution was identified, for example, by Participant 4:

So we all set up discussion boards, but some people can use them very well. We all use case studies and presentations and some of us do them better ... I think it's more about the execution, not the novelty.

I would look at blended learning more in terms of learning than support ... you know, face-to-face learning and teaching rather than as a replacement for it. (Participant 5) 
Results of the study demonstrate a prevailing perception of blended learning as employing a variety of tools and techniques in module delivery. For some participants, technology is simply a way of organising and managing information for large student numbers. According to the study, blended learning is not always perceived as a positive thing. Whereas reports of successful examples of blended learning prevail, many participants find preparation time-consuming and supporting technology prone to failure. The majority of participants are more inclined to use ICT in the areas where they can see it delivering distinct benefits, such as delivering efficiency in classroom communication and convenience to students. This research revealed that more technology-apt participants are more likely to experiment with technology and are less wary of the learning curve or potential failure.

Whilst it was rare for staff to be totally opposed to using technology, levels of experience varied greatly across the participants. At the one extreme, one participant had designed modules that 'integrated' computer-based and face-to-face techniques. Participant 13 perceived blended learning as more than a hybrid approach in which two techniques are brought together without thinking about how they work together. For this participant, the use of the term 'blended' means:

that it highlights the need to integrate them and to therefore think about the best way to actually teach this aspect of the module. And how I can bring together the face-toface and on-line aspects. (Participant 13)

In contrast to this, a singular view of purely technology focused approach emerged when Participant 9 was asked about limitations of blended learning:

None because you have to use your imagination to adapt blended learning methods to the material you are trying to teach.

In this case, teaching methods and technology were used interchangeably - suggesting that pedagogy was overshadowed by a personal interest in technology.

Findings suggested that any barriers to developing blended learning modules were not, in the main, related to attitudes; in fact, virtually all participants claimed that they would collaborate with an e-developer. Barriers appeared to be related to the perception of developing the ICT-based aspects of blended learning as time-consuming:

just initial set-up time really, rather than having to prepare a lecture and stand there and talk at the students for a couple of hours, obviously it takes more time. (Participant 16)

Additional reasons for not incorporating more ICT-based innovation into their delivery related to a lack of confidence that the technology would work:

Sometimes I use videos; sometimes it would be nice to just have a two minute clip ... it just sums up exactly what you have said in a real context, and if I could manage that, or be confident that it would work, that would be the sort of thing, yes. (Participant 8) 
Despite concerns described above, participants demonstrated an appreciation of many benefits of a technology-enabled blended learning approach as providing exciting teaching opportunities as well as catering to a variety of learning styles.

\section{What are academic staff current practices of blended learning?}

Implicit in the development of blended learning is the notion of innovation. As part of this research, participants were asked to describe any innovations they had implemented in their teaching. Some were modest in their claims; Participant 8, for example, began answering the question by stating "I don't think I use anything innovative" but was one of the first to use electronic sign-up to assign students to tutorial groups, yet this was not even mentioned in the interview, suggesting that Participant 8 did not perceive this as innovative, despite its clear benefits in managing student learning. Others saw a lack of face-to-face contact time as a barrier to innovation in the classroom. Participant 1, for example, reduced the number of student presentations as teaching time had become "too compressed".

Some of the participants also noted how difficult it is to simply add tools such as a moderated online discussion board to a module and call it blended learning. For Participant 14 this was a real situation that had left him feeling very negative. It also led him to suggesting that to successfully incorporate blended learning into a module does require a lot of administrative assistance. Yet another barrier was noted by Participant 6 , who felt that use of learning management systems could make students lazy, in particular if the tutor was providing sources rather than "letting the student investigate for himself" (Participant 6).

In addition, it was possible to identify a group of participants who, whilst supporting a wide range of learning resources and approaches to teaching, saw technology as simply a way of organising and managing information for large student numbers. This group was also characterised by a common desire for more face-toface contact time with students (Participants 1,3 and 8). They saw technology as an important tool for clear communication:

Yes, I do try and make sure it is planned so they know what's going on; they always love to know, obviously there's a plan: the module handbook, what they do in each week, lectures and tutorials [...] that's in the handbook and then, well the detail comes out on Blackboard so they have always got information. And that ... is important $[. .$.$] because if you have got large numbers and they haven't got good informa-$ tion, you are going to get 150 people asking you, which is a nightmare. So I think the module handbook and use of Blackboard as a communication tool is vital in terms of handling the large groups. (Participant 8)

A dominant view of perceiving blended learning as a mixture of teaching practices has become evident. The application of a variety of pedagogical approaches in faceto-face teaching was used mainly to capture and retain learner focus and increase effectiveness of learning. Levels of experience varied greatly across the participants, it was rare to find views that were totally against using technology. Student-centred views have been encouragingly popular; however, face-to-face teaching was still seen as a more effective way of teaching than technology based. 


\section{Discussion}

An issue emerging from both our research and other studies (for example, Bonk and Charles 2006) is the perception of developing blended learning materials as time-consuming. As the perception is not contested, and in fact has been acknowledged to reflect reality, it would seem sensible to adopt a strategy that attempts to realise the long-term benefits of investment in developing a blended approach. Whilst benefits might include more efficient management and organisation of modules, they should also include distinct benefits in the form of improved student learning and enhancement of teaching quality.

Adoption of technology by academic staff may be influenced by a variety of factors. Arguably, most academic staff seek some form of positive impact from embracing technology supporting learning and teaching. Some try to achieve differentiation (Daniel 1998), others associate quality enhancement with blended learning (DeLacey and Leonard 2002). Undoubtedly, adoption of technology has been associated with improving efficiency (Porter 1985). In the context of this study the impact of technology on effectiveness of class communication, access to learning resources and general management of students has been widely reported. Whilst not all academic staff are adventurous enough to embrace blended learning to its full potential, some see the positive impact of technology on making the most of their face-to-face teaching and utilising a wealth of resources in class or online. Evidence from the study suggests that most academic staff adopted the use of multimedia to bring interactivity and interest into the classroom. A number of academic staff integrated group work and peer-learning with the use of discussion forums. The study revealed a significant range of technology tools successfully used by academic staff who witnessed a positive impact of blended learning on student performance. Ultimately, the impact that blended learning has on students and module effectiveness appears to influence perceptions of blended learning by academic staff.

Finally, the choice of whether to adopt blended learning or not largely depends on the available resources and staff awareness about them. Although many supporting resources, such as a learning management system, automated assessment tools, wireless networks and devices are available, not all academic staff choose to take advantage of them. Others are overwhelmed by the variety of resources. For instance, one academic staff member deems it too time-consuming to venture out looking for new video case studies as the old non-interactive materials work just as well. In any case, availability of resources, including time, administrative and developmental support and technology, appears to define the way tutors adopt or shy away from blended learning.

\section{Towards a typology of blended learning practices}

In order to understand the context of academic staff perceptions and attitudes influencing adoption of blended learning, it was important to establish the drivers of their teaching practices. Key dimensions of technology and pedagogy, affecting adoption of blended learning strategies by academics, were linked to create twodimensional typologies (Ritchie and Spencer 2002) of approaches to blended learning. Technological drivers impacting on academics' approaches to teaching ranged from proven resources or technology that have been used for a significant period of time and are familiar to the majority of users through to technology so novel that 
the enthusiasm about its novelty may overshadow its lack of reliability or usefulness in the context of use. Pedagogical drivers were viewed as ad hoc at one extreme, where methods of delivery were less thought through, through to a more strategic approach, where the choice of teaching methods was driven by the desire to achieve learning goals. Analysis of the findings revealed the existence of three distinct types amongst the participants. Based on their views of pedagogy and technology, as well as resources and perceptions of blended learning impact, it was possible to cluster participants according to their choice of drivers and expectations from blended learning.

The following distinct approaches have emerged from our analysis: 'Technology is all', 'The bolt-ons' and 'Purely pedagogic'. The vignettes below summarise the characteristics of each type:

\section{'Technology is all'}

This group was a small cluster of technology-driven academic staff who embraced each new tool with enthusiasm, striving to include them in their existing practice. They saw no limit to the possibilities of technology and, whilst acknowledging the importance of student learning, they were driven by the new technology rather than the strategic impact on student learning.

\section{'Bolt-ons'}

This group tended to use technology as a 'bolt-on' to improve their teaching (by more effectively managing student groups) or the students' learning (by using technology to add variety to their delivery). They certainly did not regard technology as a substitute for teaching. Indeed, for this group, the pedagogy was deemed more important than the need for technology. This group would typically draw upon examples of non-technological innovation in their teaching (participative workshops, guest speakers) to stress that they saw themselves as using a blended approach despite their reluctance to invest time in learning how to use technological tools. This was the largest group within the participants.

\section{'Purely pedagogic'}

A very small group within the participants appeared to start by thinking about pedagogy, then developing materials (both in-class and out of class) to ensure effective student learning. Sometimes the solutions would involve sophisticated technology, other times innovations would be classroom based. This group did not express any concerns about embracing technology and learning about new tools, but, unlike the 'Technology is all' group, would select their techniques on the basis of pedagogy and student learning rather than technology.

Whilst this paper does not seek to make judgements about the different typologies, one of the decisions that the institution must face is whether one type is preferable to another. Is there a need to encourage staff towards the 'Purely pedagogic' type and if so what are the implications for staff development? Currently, at the research site, there are numerous workshops where academic staff can learn how to make podcasts, how to set up social networks, how to use electronic assessment, 
and so forth. Arguably this can provide the 'Bolt-ons' with more tools, but does it encourage consideration of the underlying pedagogy?

\section{Conclusions}

\section{What are academic staff perceptions of blended learning?}

Whilst most academic staff interviewed understood the inclusion of some technology implied in definitions of blended learning, for many of them blended learning was much wider than simply amalgamating a number of electronic and web-based tools and resources. A number commented on the fact that they had always approached their teaching by considering variety in delivery. Results of the study demonstrate a prevailing perception of blended learning as employing a variety of tools and techniques in module delivery. Some academic staff see technology as simply a way of organising and managing information for large student numbers. According to our study, blended learning is not always perceived as a positive thing. Although reports of successful examples of blended learning prevail, many academic staff find the preparation stage time-consuming and supporting technology prone to failure. Staff are more inclined to use ICT in the areas where they can see that it delivers distinct benefits. Such practices aimed at delivering efficiency in classroom communication and convenience of access to information for students. This research revealed that academic staff more adept with technology are more likely to experiment with technology and are less wary of the learning curve or potential failure. A rather extreme view of pedagogy as technology alone motivated some academic staff into experimenting with technology without appropriate pedagogical underpinning.

\section{What are academic staff attitudes towards blended learning?}

Findings suggested that barriers to developing blended learning modules were unrelated to attitudes; in fact, almost all participants agreed that they would collaborate with an e-developer. Although levels of experience varied greatly across the academic staff, it was rare to find views that were totally against using technology. Barriers appeared to be related to the perception of developing the technology-based aspects of blended learning as time-consuming, including difficulties in locating relevant resources as so many are now available on the web. Despite these concerns, many participants demonstrated an appreciation of the benefits of a technologyenabled blended learning approach in providing exciting teaching opportunities as well as catering to a variety of learning styles.

\section{What are academic staff current practices of blended learning?}

A dominant view of perceiving blended learning as a mixture of teaching practices has become evident. The application of a variety of pedagogical approaches in face-to-face teaching was used mainly to capture and retain learner focus and increase effectiveness of learning. Beyond the classroom settings, discussion boards and podcasts, video materials and provision of resource access through the learning management system were among most widely reported tools that enabled casestudy-based teaching, action learning and facilitating group work. A significant 
number of participants voiced the view for more complex and engaging collaborative resources, such as games and simulations. There was a wish to extend the range of pedagogical and technological approaches if barriers could be overcome.

\section{Recommendations}

From the academic staff perspective, blending technology and traditional teaching methods represents a significant challenge (Vaughan 2007). Current teaching practices involve substantial classroom interaction, case studies, student group work and presentation, simulations, and so on. Blended learning as a seamless mixture of face-to-face and technology-facilitated methods of delivery appears to be well suited to address the needs of academic staff teaching varying numbers of students, in different classroom settings, addressing a range of learning styles and cultural differences. The study evaluated the current state of teaching practices and helped shed some light on the progression of implementation of a blended learning strategy at the Business School. The study findings confirm previous research on staff perceptions that blended learning is time-consuming but that staff are inclined to use technology where they can see the benefits. Hence any strategy implementation needs to address staff concerns and identify innovations likely to be beneficial in the specific context.

Factors affecting the integration of blended learning stemmed from the attitudes and perceptions of academic staff towards new teaching practices and technologies. The perceived impact, whether positive (e.g. increased efficiency of the communication process with students) or negative (e.g. extra administrative effort and time investment in content development), appeared to have the driving effect on blended learning adoption. Availability of resources such as time, technology and support of e-developers also surfaced as determinants of positive attitudes towards adopting new teaching practices.

It is conceivable that a study at other higher education institutions may yield different results; however, this case study certainly provides a useful insight into the factors facilitating or impeding implementation of the blended learning strategy from the academic staff perspectives.

The challenge for institutions implementing blended learning strategies is to build on positive staff attitudes, provide appropriate resources and help staff develop blends of teaching practices and use of technologies that deliver the best outcomes in particular teaching and learning contexts.

\section{References}

Alebaikan, R., and S. Troudi. 2010. Blended learning in Saudi universities: Challenges and perspectives. ALT-J, Research in Learning Technology 18, no. 1: 49-59.

Arbaugh, J.B. 2008. Introduction: Blended learning: Research and practice. Academy of Management Learning \& Education 7, no. 1: 130-1.

Bates, A.W. 2000. Managing technological change. Strategies for college and university leaders. San Francisco: Jossey-Bass.

Bleed, R. 2001. A hybrid campus for a new millennium. Educause Review 36, no. 1: 16-24.

Bonk, C.J., and G. Charles. 2006. The handbook of blended learning: Global perspectives, local designs. San Francisco: John Wiley and Sons.

Boyle, T., C. Bradley, P. Chalk, R. Jones, and P. Pickard. 2003. Using blended learning to improve student success rates in learning to program. Journal of Educational Media 28, no. $2-3$ : $165-78$. 
Charles, D., and P. Anthony. 2007. Blended learning: Research perspectives. Needham, MA: Sloan Center for OnLine Education.

Clark, D., 2003. Blend it like Beckham. Epic Group PLC. http://www.epic.co.uk/content/resources/white papers/blended.

Cuban, L., H. Kirkpatrick, and C. Peck. 2001. High access and low use of technologies in high school classrooms: Explaining an apparent paradox. American Educational Research Journal 38, no. 4: 813-34.

Daniel, J. 1998. Mega-universities and knowledge media: Technology strategies for higher education. London: Kogan Page.

DeLacey, B., and D. Leonard. 2002. Case study on technology and distance in education at the Harvard Business School. Educational Technology and Society 5, no. 2: 13-28.

Derntl, M., and R. Motschnig-Pitrik. 2005. The role of structure, patterns, and people in blended learning. The Internet and Higher Education 8, no. 2: 111-30.

Dziuban, C., J. Hartman, and P. Moskal. 2004. Blended learning. Educause Center for Applied Research Bulletin 7: 1-12.

Garrison, D.R., and T. Anderson. 2003. E-learning in the 21st century: A framework for research and practice. London: RoutledgeFalmer.

Garrison, D.R., and H. Kanuka. 2004. Blended learning: Uncovering its transformative potential in higher education. The Internet and Higher Education 7, no. 2: 95-105.

Garrison, D.R., H. Kanuka, and D. Hawes. 2002. Blended learning: Archetypes for more effective undergraduate learning experiences. Report. University of Calgary, Learning Commons.

Hannon, J. 2008. Doing staff development: Practices, dilemmas and technologies. Australasian Journal of Educational Technology 24, no. 1: 15-29.

Higher Education Funding Council for England. 2005. HEFCE strategy for e-learning. Statements of policy March 2005/12. http://www.hefce.ac.uk/pubs/hefce/2005/05.

Kvale, S. 1996. InterViews: An introduction to qualitative research interviewing. London: Sage.

Oliver, M., R. Sharpe, J. Duggleby, D. Jennings, and D. Kay. 2004. Accrediting learning technologists: A review of the literature, schemes and programmes. ALT Accreditation Project Report 1. Oxford: Association for Learning Technology.

Oliver, M., and K. Trigwell. 2005. Can 'blended learning' be redeemed? E-Learning 2, no. 1: $17-26$.

Ooms, A., L. Burke, T. Linsey, and C. Heaton-Shrestha. 2008. Introducing e-developers to support a university's blended learning developments. ALT-J, Research in Learning Technology 16, no. 2: 111-22.

Pajo, K. 2001. Barriers to the uptake of web-based technology by university teachers. Journal of Distance Education 16, no. 1: 70-84.

Porter, M.E. 1985. Competitive advantage: Creating and sustaining superior performance. New York: The Free Press.

Ritchie, J., and L. Spencer. 2002. Qualitative data analysis for applied policy research. In qualitative researcher's companion, eds. M. Huberman, and M. Miles. Thousand Oaks, CA: Sage Publications.

Rogers, E. 1995. Diffusion of innovations. New York: The Free Press.

Rovai, A.P., and H.M. Jordan. 2004. Blended learning and sense of community: A comparative analysis with traditional and fully online graduate courses. The International Review of Research in Open and Distance Learning 5, no. 2: 1-13.

Sharpe, R., G. Benfield, G. Roberts, and R. Francis. 2006. The undergraduate experience of blended e-learning: A review of UK literature and practice. Higher Education Academy. http://www-new2.heacademy.ac.uk/assets/York/documents/ourwork/research/literature reviews/blended_elearning full_review.pdf.

Vaughan, N. 2007 Perspectives on blended learning in higher education. International Journal of e-Learning 1: 81-94. http://www.thefreelibrary.com/Perspectivesonblendedlearninginhighereducation.-a0159594390 (accessed September 28, 2010).

Williams, C. 2002. Learning on-line: A review of recent literature in a rapidly expanding field. Journal of Further and Higher Education 26, no. 3: 263-72.

Wu, J.H., R.D. Tennyson, and T.L. Hsia. 2010. A study of student satisfaction in a blended e-learning system environment. Computers \& Education 55: 155-64. 